\title{
Análise da formação pedagógica Lato Sensu em Direito Sanitário da Escola Fiocruz de Governo - Fiocruz Brasília
}

\author{
Analysis of the pedagogical formation Lato Sensu in Sanitary Law of the Fiocruz School of \\ Government - Fiocruz Brasília
}

Análisis de la formación pedagógica Lato Sensu en Derecho Sanitario de la Escuela Fiocruz de Gobierno - Fiocruz Brasilia

RESUMO. Objetivo: O artigo analisou a formação pedagógica da especialização em Direito Sanitário da Escola de Governo em Saúde - Fiocruz Brasília, no período de 2006-2015. Metodologia: A pesquisa consistiu em um estudo analítico-descritivo, de caráter qualiquantitativo, baseado em pesquisa documental secundária. Foram analisados os relatórios acadêmicos e o questionário de avaliação pedagógica, realizada com os egressos. Resultados: As análises evidenciaram que houve crescimento pela procura de vagas nos processos seletivos, assim como a participação de egressos oriundos da área tanto do Direito como da Saúde. Conclusão: A implantação do curso se deu de forma exitosa, e que a especialização oferece relevantes contribuições para a qualificação de profissionais da área da saúde e demais interessadas.

Palavras-chaves: Educação em Saúde. Direito Sanitário. Capacitação de Recursos Humanos em Saúde.

ABSTRACT. Objective: The study analyzed the pedagogical training of the Specialization in Sanitary Law of the School of Government in health - Brasília, in the period from 2006 to 2015. Methodology: The research consisted of an analytical-descriptive, qualitativequantitative study, based on secondary documentary research. We analyzed the academic reports and the pedagogical evaluation questionnaire, with the graduates. Results: The analyzes showed that there was growth in the search for vacancies in the selective processes, as well as the participation of graduates from both the Law and Health area. Conclusion: It was concluded that the implementation of the course was successful, and that specialization offers relevant contributions for the qualification of health professionals and others interested.

Keywords: Education in Health. Health Law. Health Human Resource Training.

RESUMEN. Objetivo: El estudio analizó la formación pedagógica de la especialización en Derecho Sanitario de la Escuela de Gobierno en salud- Brasilia, en el período de 2006 a 2015. Metodología: La investigación consistió en un estudio analítico-descriptivo, de carácter cual-cuantitativo, basado en investigación documental secundaria. Se analizaron los informes académicos y el cuestionario de evaluación pedagógica, realizada con los egresados. Conclusión: Se concluye que la implantación del curso se dio de forma exitosa, y que la especialización ofrece relevantes contribuciones para la calificación; número de profesionales del área de la salud y demás interesadas.

\footnotetext{
${ }^{1}$ Graduada em Saúde Coletiva pela Universidade de Brasília (UnB). E-mail: lucianagoliveira7@gmail.com
} 
Palabras-Ilave: Educación en Salud. Derecho Sanitario. Capacitación de Recursos Humanos en Salud.

\title{
Introdução
}

No Brasil, há dois tipos de Pós-Graduação: Lato Sensu e a Stricto Sensu. A primeira menção a essa etapa de formação ocorreu na Lei de Diretrizes e Bases (LDB), Lei oㅜ 4.024, de 22 de dezembro de 1961, que diferenciou o acesso à graduação, à pós-graduação, à especialização, ao aperfeiçoamento e aos cursos de extensão (1).

A partir da década de 1990, houve um acelerado aumento dos cursos de especialização nas modalidades stricto e lato sensu que:

\begin{abstract}
Diante da nova conjuntura do mercado de trabalho com forte influência do processo de globalização e da permanente necessidade de capacitação técnico-profissional dele decorrente, as instituições de ensino públicas e privadas passaram a desenvolver atividades de capacitação em todas as áreas do conhecimento, utilizando-se largamente dos cursos de pósgraduação lato sensu (2).
\end{abstract}

Os cursos Lato Sensu são a especialização e aperfeiçoamento que possuem objetivo técnico profissional específico como finalidade em campo eminentemente prático. Os cursos devem ter duração mínima de 360 horas (3).

A Resolução no 1, de 3 de abril de 2001, do Ministério da Educação, elaborada com base no espírito de flexibilização do ensino superior, estabelece parâmetros mínimos para o funcionamento dos cursos de pós-graduação, quais sejam: I - oferta de cursos de pósgraduação lato sensu, independendo de autorização, reconhecimento, e renovação de reconhecimento; II - inclusão na categoria de cursos lato sensu os cursos designados como MBA (Master Business Administration) ou equivalentes; III- supervisão dos órgãos competentes a ser efetuada por ocasião do recredenciamento da instituição; IV- duração mínima de 360 horas; V- frequência de $75 \%$. VI- corpo docente constituído necessariamente por, pelo menos, $50 \%$ de professores portadores de título de mestre ou de doutor, obtido em programa de pós-graduação stricto sensu reconhecido; VII - oferta aberta a portadores de diploma de curso superior; e VIII - os cursos de pós-graduação lato sensu ficam sujeitos à supervisão dos órgãos competentes a ser efetuada por ocasião do recredenciamento da instituição (4). 
No que tange ao cadastro de oferta de pós-graduação lato sensu (presencial e a distância) para todas as instituições credenciadas no sistema de ensino federal, a Resolução no 2, de 12 de fevereiro de 2014 é que normatiza. Dentre as principais obrigatoriedades estão: fornecer dados sobre o corpo docente, nome do coordenador, número de vagas e periodicidade dos cursos de especialização lato sensu para propor políticas e regulamentações necessárias para qualificar a oferta de curso (4) (5).

A Fundação Oswaldo Cruz (Fiocruz), instituição vinculada ao Ministério da Saúde, é uma das instituições públicas que ofertam cursos de especialização. Esta realiza os seus cursos no cumprimento da Lei no 5019, de 07 de junho de 1966 (6), que autoriza o Poder Executivo a instituir a Fundação Ensino Especializado de Saúde Pública, e do Decreto nº 66.624, de 22 de maio de 1970, que autoriza capacitar recursos humanos na área da saúde.

Em Brasília, a representação do órgão Fiocruz fica à cargo da Gerência Regional de Brasília (Gereb) também conhecida como Fiocruz Brasília, que capacita recursos humanos na área da saúde. A instituição foi definida pelo Decreto ํㅜ 8.932 de 14 de dezembro de 2016, que apresenta a estrutura e as atribuições da gerência regional.

De acordo com o art.30 do Decreto, a Gerência Regional de Brasília compete:
II - Estabelecer parcerias com instituições de ensino, pesquisa e saúde e de execução de políticas públicas para ciência e tecnologia, articular e apoiar redes sociotécnicas e as unidades da Fiocruz;
VII - realizar atividades de ensino e pesquisa aplicada, dirigidas à governança e à gestão de políticas públicas e saúde. (7)

A primeira turma do curso de especialização em Direito Sanitário foi realizada em parceria com a Escola Nacional de Saúde Pública Sergio Arouca (ENSP), em 2002. E em 22 de junho de 2005, a secretaria acadêmica da Gereb já recebia a proposta acadêmica para tramitação interna. (8)

A turma surgiu de uma demanda da Secretaria de Saúde do Distrito Federal, para a capacitação dos inspetores sanitários da Diretoria de Vigilância Sanitária. Ao longo dos anos, o curso se expandiu e se estendeu as demais áreas da saúde coletiva, devido à grande procura.

A especialização em Direito Sanitário, realizado na Fiocruz Brasília, tem por objetivo capacitar o corpo discente com conhecimentos jurídico-político-sanitários de forma a desenvolver expertise para compreensão e atuação nas questões sanitárias contemporâneas. (9) 
Segundo Aith (10), o Direito Sanitário nasceu do resultado do diálogo social que relaciona o direito e a saúde.

[...] O Direito Sanitário é a leitura jurídica que a sociedade faz sobre a questão da saúde, individual ou coletiva, resulta, portanto dos esforços da sociedade para organizar um conjunto de normas jurídicas capaz de tornar previsíveis as atividades relacionadas com a promoção, proteção e a recuperação da saúde. Ele é orientado a regular e direcionar tais atividades para garantir a todos a realização do direito à saúde em um ambiente democrático de proteção dos direitos humanos fundamentais. [...] O Direito Sanitário também organiza a forma como o Estado e a iniciativa privada irão desenvolver ações de serviços de saúde, bem como a forma se dará a fiscalização e o controle dessas ações e serviços.

Diante deste contexto, o objetivo deste artigo é avaliar e discutir o processo pedagógico e acadêmico do curso de especialização em Direito Sanitário.

\section{Metodologia}

Tratou-se de estudo analítico-descritivo, de caráter quali-quantitativo, baseado em pesquisa documental secundária e bibliográfica.

Foi utilizado um questionário de avaliação pedagógica, elaborado e enviado por e-mail para os egressos da segunda até a oitava turma do curso de especialização (2006-2015). O objetivo do questionário foi fazer uma análise do curso ao longo dos anos, de acordo com a opinião dos egressos que cursaram a especialização. Foram extraídas as seguintes informações: idade, cidade em que reside, gênero, graduação, principal razão para fazer o curso, se já possuem doutorado e mestrado, também foram citados avaliação do corpo docente, trabalho de conclusão de curso e atividades profissionais. A pesquisa foi realizada no $1^{\circ}$ semestre de 2016.

Os procedimentos de sistematização e análises dos dados obtidos pelos questionários foram organizados em tabelas e gráficos. Foram lidos os trabalhos de conclusão de curso disponíveis na biblioteca da Fiocruz e foram analisados, com leitura dos títulos e resumo. Nem todos os trabalhos estavam disponíveis para leitura, muitos deles encontravam-se na posse da Secretaria Acadêmica da Escola Fiocruz de Governo Brasilia (Secad/EFG), a qual negou acesso aos trabalhos. 
As áreas do conhecimento foram classificadas conforme estabelecido pela Fundação Coordenação de Aperfeiçoamento de Pessoal de Nível Superior (Capes) e o Conselho Nacional de Desenvolvimento Científico e Tecnológico (CNPq).

Foram realizadas análise e leitura exaustiva de relatórios acadêmicos, disponibilizados pela Coordenação do Curso, a fim de identificar o perfil do egresso e das turmas.

A identidade dos participantes foi mantida em sigilo, conforme compromisso assumido perante a Comissão Nacional de Ética e Pesquisa (Conep), conforme processo $\mathrm{n}^{\circ}$ 1.523.096/2016. A coleta de dados ocorreu entre julho e setembro de 2017.

\section{Resultados e Discussão}

O curso foi apresentado e estruturado pelo Programa de Direito Sanitário (Prodisa), a partir da $2^{a}$ turma, em 2006. Desde então, vem desenvolvendo ações de grande relevância social que estimulam a produção do conhecimento científico. Ademais, os cursos de especialização lato sensu têm importância formativa no campo técnico-profissional e na educação continuada, e vêm sendo desafiados pela reconfiguração metodológica da ciência e das diferentes funções atribuídas ao conhecimento, considerando a sua articulação direta com o mercado e com o desenvolvimento social (2).

Desde 2006, oito turmas foram concluídas e 178 alunos obtiveram o título de especialista em Direito Sanitário. A cada ano o processo seletivo é mais concorrido e há uma grande procura, por vários segmentos, dentre estes alunos recém-formados de graduação, docentes, funcionários do setor privado, público - tanto do âmbito federal, estadual, municipal, como distrital, buscando além do aperfeiçoamento, qualificação nos estudos e capacitação profissional.

O questionário foi enviado, por e-mail, a 181 egressos do curso de especialização. Deste total, 120 egressos responderam, sendo 76 do sexo feminino e 44 do sexo masculino. Verifica-se a predominância das mulheres no curso.

De acordo com os dados, $38 \%$ dos egressos tinham entre 31 e 40 anos, $26 \%$ tinham entre 41 e 50 anos, e 19\% entre 20 e 30 anos. Acima de 50 anos, observou-se apenas 17\%. Quanto a Unidade de Federação (UF), 87,5\% residem no Distrito Federal e 12,5\% em outros Estados. 
Com relação à formação superior, constatou-se uma diversidade nos cursos e $22,5 \%$ desses egressos estavam na segunda graduação. Como descritos no quadro 1 , foram identificados 24 diferentes cursos de graduação.

Quadro 1 - Áreas do conhecimento e graduação dos egressos

\begin{tabular}{|c|c|c|c|}
\hline Área do Conhecimento & Área de graduação & $\begin{array}{l}\text { Quantidade de alunos que } \\
\text { cursaram os respectivos } \\
\text { cursos }\end{array}$ & Total \\
\hline Ciências Exatas e da Terra & Computação & 1 & 1 \\
\hline Ciências Biológicas & Ciências Biológicas & 1 & 1 \\
\hline Engenharias & Engenharia Cívil & 1 & 1 \\
\hline Ciências da Saúde & $\begin{array}{l}\text { Enfermagem } \\
\text { Fisioterapia } \\
\text { Farmácia } \\
\text { Medicina } \\
\text { Nutrição } \\
\text { Odontologia } \\
\text { Saúde Coletiva }\end{array}$ & $\begin{array}{c}9 \\
2 \\
16 \\
5 \\
3 \\
6 \\
10 \\
\end{array}$ & 51 \\
\hline Ciências Agrárias & $\begin{array}{l}\text { Engenharia dos Alimentos } \\
\text { Engenharia Agronômica } \\
\text { Medicina Veterinária }\end{array}$ & $\begin{array}{l}1 \\
1 \\
2\end{array}$ & 4 \\
\hline Ciências Sociais Aplicadas & $\begin{array}{l}\text { Administração } \\
\text { Arquitetura e Urbanismo } \\
\text { Comunicação Social } \\
\text { Direito } \\
\text { Economia }\end{array}$ & $\begin{array}{c}5 \\
1 \\
1 \\
34 \\
1\end{array}$ & 42 \\
\hline Ciências Humanas & $\begin{array}{l}\text { Ciências Sociais } \\
\text { História } \\
\text { Psicologia } \\
\text { Relações Intemacionais }\end{array}$ & $\begin{array}{l}4 \\
1 \\
4 \\
1\end{array}$ & 10 \\
\hline Lingüística, Letras e Artes & Letras & 5 & 5 \\
\hline Outros & $\begin{array}{l}\text { Administração Hospitalar } \\
\text { Biom edicina }\end{array}$ & $\begin{array}{l}2 \\
2\end{array}$ & 4 \\
\hline
\end{tabular}

Fonte: Elaborado pelas autoras, com base no questionário de avaliação pedagógica do curso de Direito Sanitário respondido pelos egressos no $1^{\circ}$ semestre de 2016. 
Verifica-se que o maior número de graduados foi do curso de Direito, com $28,3 \%$. O Direito em função da natureza da especialização concentra profissionais que já atuam nesta área, oriundos de órgãos do Ministério Público Federal, Ministério da Saúde, Ministério da Justiça, entre outros. Os interesses deste segmento colocam em prática o que vivenciam no cotidiano, aspectos relacionados com a temática da especialização. Importante ressaltar que, apesar do maior número de graduados ser do curso do direito, o seu escopo e sua relevância social permitiram o interesse de profissionais com diversas formações.

A formação de profissionais da área da saúde tem aumentando significativamente. Foram identificados, conforme quadro 1, egressos com formação em farmácia, saúde coletiva, enfermagem, odontologia, medicina, nutrição e fisioterapia, totalizando 42,5\% dos respondentes. Esse dado evidencia que a área de conhecimento Ciências da Saúde está na frente em relação à quantidade de egressos pertencentes à área das Ciências Sociais Aplicadas. Observa-se que 8,3 \% são da área das Ciências Humanas, 3,3\% das Ciências Agrárias, 4,1\% Linguística, Letras e Artes, 1\% para Ciências Exatas, Biológicas e Engenharias - o mesmo percentual para ambas.

Na sétima e oitava turma da especialização os graduados em Saúde Coletiva foram os que mais procuraram o curso. O curso de Saúde Coletiva é um curso novo, implementado em 2010, na Universidade de Brasília pelo Departamento de Saúde Coletiva (DSC), da Faculdade de Ciências da Saúde (FS). O bacharel em saúde coletiva tem por finalidade atender às necessidades do Sistema Único de Saúde, contribuindo para o fortalecimento da capacidade de gestão dos serviços de saúde (11).

O curso pode ser compreendido como um campo interdisciplinar de produção e utilização de conhecimentos sobre a problemática da saúde-doença-cuidado, que, servindose da Epidemiologia, das Ciências Sociais em Saúde e do Planejamento e Gestão em Saúde agregado aos conhecimentos jurídico-legais forma o aluno para atuar em situações fáticas da gestão da saúde.

A disciplina de Direito Sanitário faz parte da grade curricular dos alunos de graduação de Saúde Coletiva e, talvez, pela qualificação e interesse pela área, tem-se atraído recémgraduados para a especialização, mostrando que a interdisciplinaridade do campo Saúde e Direito Sanitário é, mais que uma realidade, uma necessidade.

São poucas instituições que ofertam cursos com a temática do direito e a saúde. A Região Sudeste é a que mais oferece cursos regulares no campo do conhecimento da 
especialização Lato Sensu em Direito Sanitário. E, de modo geral, o tema Direito Sanitário está inserido basicamente na área da saúde pública e não no campo do Direito (12). Embora o foco do Direito Sanitário seja as ações que envolvem a saúde, sua essência é fundamentalmente jurídica.

De acordo com Amaral (12), a interdisciplinaridade é um fenômeno comum na área do Direito, pois diferentes ramos especializados da Ciência Jurídica se cruzam, se interpenetram e se relacionam entre si para uma aplicação mais adequada do Direito, que faça jus à complexidade social. Alves afirma (13) que a interdisciplinaridade surge como alternativa ao saber compartimentalizado, sendo o direito sanitário um exemplo positivo dessa necessária interação e diálogo entre campos do conhecimento distinto.

Segundo os questionários, foram apontados que além da formação da graduação, 34\% dos alunos detinham o título de especialista e 12,7 \% o título de mestre. Chama a atenção que $40 \%$ dos alunos que concluíram o mestrado e o doutorado estudaram na Universidade de Brasília.

Os critérios de motivação e as principais razões que levaram a escolha pelo curso de especialização, 69\% dos egressos afirmaram que foi para melhorar o nível profissional no mercado de trabalho, e depois da especialização, 21\% acabaram recebendo promoção e aumento salarial. Para 10\% o título de especialista tinha o objetivo de complementar a graduação e 8\% estão em busca da carreira de docente.

Com relação à produção científica, $25 \%$ dos alunos tiveram seus trabalhos de conclusão de curso apresentados em algum evento científico. O curso de certa forma incentiva e influência o aluno, em produzir seus conhecimentos, participando de congressos científicos e apresentação de trabalho em eventos. Os incentivos pela continuação aos estudos após a finalização da especialização levaram $29 \%$ do egresso a começar outra pósgraduação, isso significa que o retorno que o aluno teve em sala de aula serviu de base para continuar no percurso acadêmico.

Ao coordenador do curso cabe conhecer as áreas do conhecimento, entre elementos didáticos essenciais, para o aprimoramento do curso, a interlocução entre os conteúdos disciplinares e o mundo do trabalho. Além de ter conhecimento referente às normas institucionais e os pareceres do Conselho Nacional de Educação, de modo a propor alterações no projeto político pedagógico do curso (2). O projeto político pedagógico é 
referido como meio para se definir as prioridades para a gestão de cursos em sua dimensão interna e externa.

Gráfico 3 - Número de participantes do processo seletivo por ano

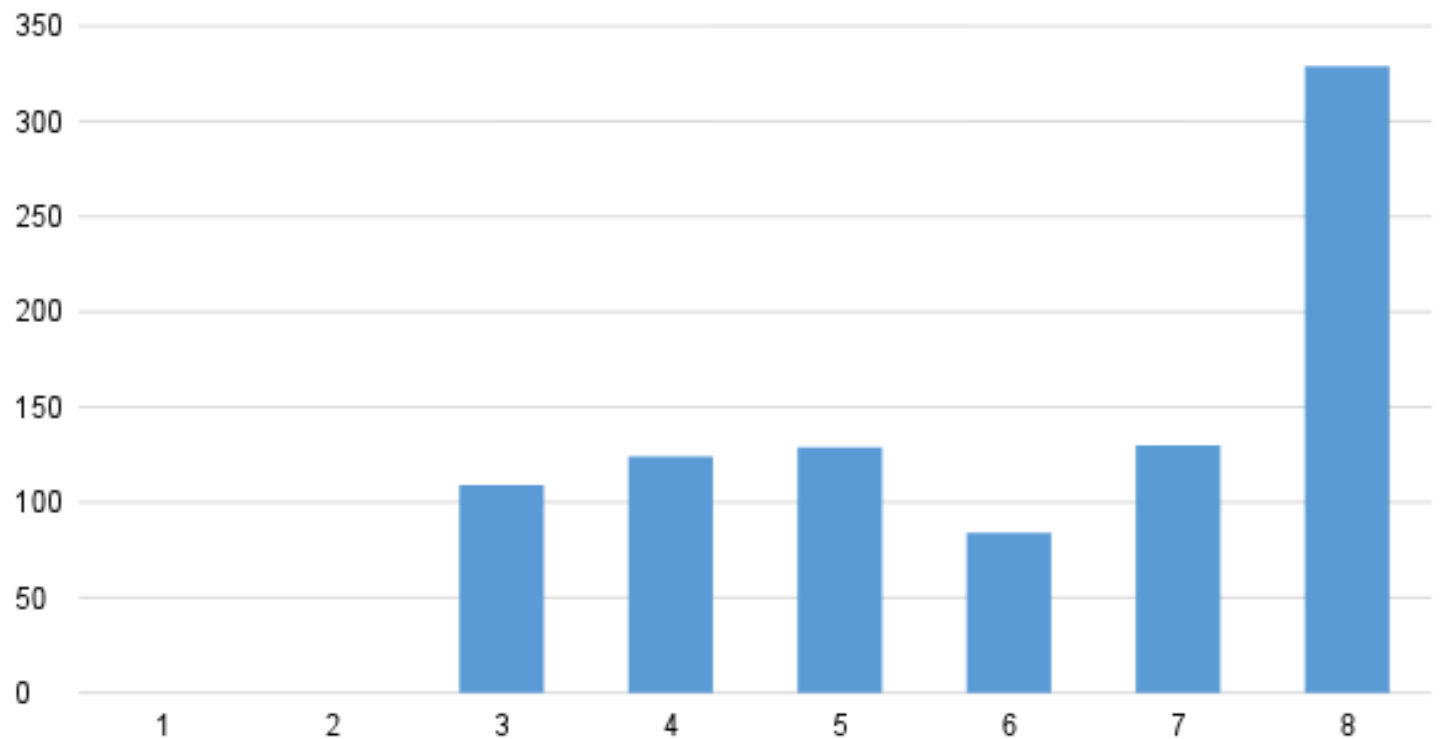

Fonte: Elaborado pela autora, com base nos relatórios acadêmicos disponibilizados pela secretária da Escola de Governo em Saúde, Fiocruz Brasília.

O número de inscrições nos processos seletivo de discentes por edital foi crescente conforme apresentado no gráfico 3. O ano de 2015 foi o que obteve o maior número de inscritos no processo, 329 candidatos disputaram uma das 30 vagas ofertadas, gerando uma média de 10,9 candidatos por vaga, a mais concorrida de todos os anos. Dos 30 alunos matriculados na oitava turma, 25 concluíram o curso. Mostrando uma evasão de $16 \%$. As atividades do curso iniciaram-se no dia 15 de abril e foram finalizadas em 11 de dezembro de 2015 (14).

A estrutura curricular foi composta com 19 disciplinas: (Elementos da Epidemiologia, Noções gerais do Direito, Saúde e Doença, Direito Sanitário I, Direito Constitucional Sanitário, Direito Sanitário II, Democracia e Saúde, Direito Administrativo Sanitário, Metodologia da pesquisa em Direito Sanitário III, Direito Regulatório da Saúde, Vigilância em Saúde, Políticas de Saúde: Teoria e Prática, Direito Civil Sanitário, Direito Internacional Sanitário, Direito Penal Sanitário, Ambiente e Saúde, Gestão e Planejamento em Saúde, Fundamentos da Ética e Bioética, Trabalho de conclusão de curso). As disciplinas ofertadas 
durante o período letivo do curso tiveram avaliação satisfatória, conforme apontados nos questionários, 50 \% considerou muito bom, 30 \% ótimo e $20 \%$ bom. Não foram citados pelos alunos avaliação negativa em relação as disciplinas.

Em todas as turmas a carga horária das disciplinas foi de 20 horas-aulas, com exceção do Trabalho de Conclusão de Curso que foi 100 horas. No total foram ministradas em média 480 horas/aulas. Em algumas turmas devido a grade curricular com menor número de disciplinas, o total foram de 460 horas/aulas. As aulas foram ministradas por docentes que possuíam título de especialização, mestrado e doutorado.

Segundo o questionário avaliado, no que condiz a competência e relacionamento com os docentes, 59\% dos alunos consideraram a relação muito bom, 21 \% ótimo e 19 \% bom. Os professores foram avaliados de forma satisfatória pelos alunos.

O modelo de trabalho de conclusão de curso na especialização nos anos de 2006, 2008, 2009 e 2011 foi a apresentação de monografia. A partir de 2012 foi adotado como modelo de TCC o artigo científico. Tal modelo permitiu a organização de dados, de modo que os alunos finalizassem o curso com um material passível de publicação. Essa estratégia serviu de incentivo para o aluno dar continuidade ao seu processo de formação acadêmica.

Gráfico 4 - Número de discentes por ano e turma

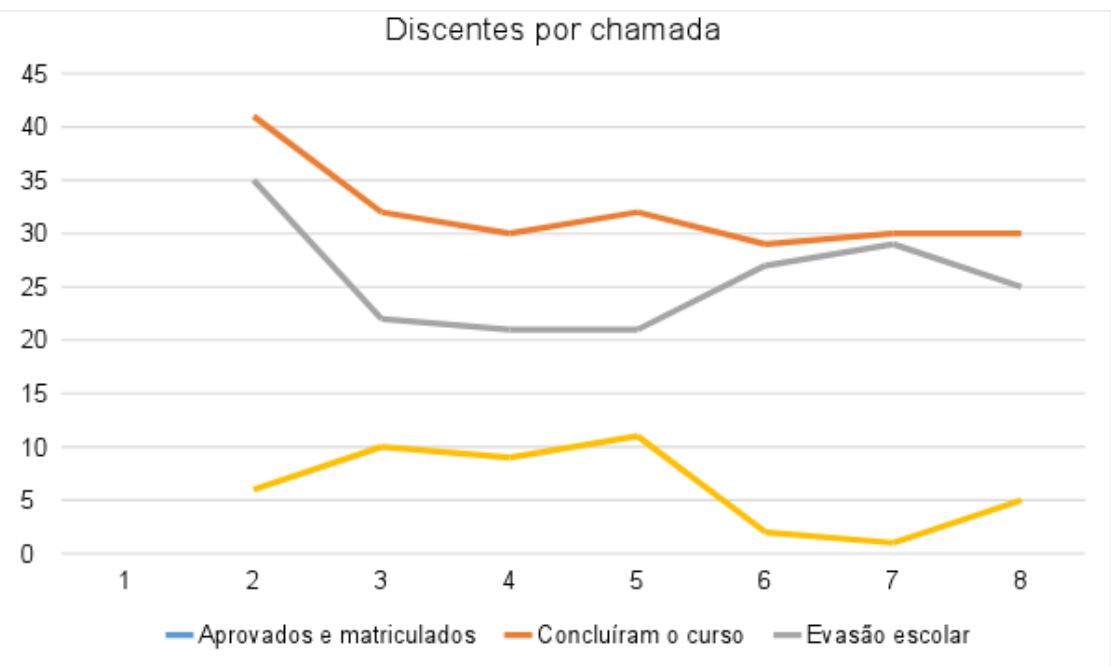

Fonte: Elaborado pela autora, com base nos relatórios acadêmicos disponibilizados pela secretária da Escola de Governo em Saúde.

A segunda turma teve início em 8 de fevereiro de 2006 e foi finalizado em 21 de dezembro do mesmo ano (15). Foram ofertadas 39 vagas aos servidores da vigilância 
sanitária do Distrito Federal e cinco vagas para o público geral, totalizando 41 matriculados. Por se tratar de turma fechada para os servidores da vigilância sanitária, não houve oferta aberta ao público.

A estrutura curricular do curso foi composta por 16 disciplinas, 460 horas - aulas, sendo 100 horas de TCC. Concluíram o curso 35 alunos. Um discente solicitou o trancamento de matricula. Reprovado em disciplina, um aluno, não apresentou o TCC e consequentemente não concluíram o curso, cinco alunos. No total 14\% da turma não concluíram o curso.

Em 2008, participaram do processo seletivo da terceira turma 109 pessoas no qual disputavam uma das 32 vagas ofertadas, uma demanda de 3,4 candidatos por vaga. A estrutura curricular foi composta por 17 disciplinas, com 480 horas-aulas (16). Concluíram o curso, 22 alunos. As atividades do curso iniciaram - se em 03 de abril de 2008 e finalizaram em setembro de 2009. Dos 32 alunos matriculados, 32,25\% não concluíram o curso. Segundo o relatório acadêmico, um aluno entrou com pedido de cancelamento da matrícula. Reprovado por falta e nota, um aluno, e outros sete não apresentaram o TCC, e consequentemente não concluíram o curso com aproveitamento.

Destaca-se que no mesmo ano o curso passou a cumprir o dispositivo da Resolução no 1 de 08 de junho 2007, do CNE/MEC. A resolução estabelece normas para o funcionamento de cursos de pós-graduação lato sensu, em nível de especialização.

O processo seletivo para a quarta turma ocorreu em 2009 e contou com a participação de 124 candidatos, resultando 30 selecionados, uma demanda de 4,1 candidatos por vaga. Este grupo contou com a participação de um aluno estrangeiro convidado. A estrutura curricular foi composta por 20 disciplinas. As atividades do curso iniciaram - se em 02 de abril e finalizaram em julho de 2010. Concluíram o curso 21 alunos. Nesta turma $30 \%$ dos alunos não concluíram o curso, segundo o relatório deste mesmo ano, a razão foi devido a solicitação de trancamento de matricula feita por três alunos (17). Dois discentes reprovaram por falta e nota nas disciplinas e outros quatro não obtiveram aprovação no TCC.

A quinta turma de especialização abriu o processo seletivo para o preenchimento de 32 vagas, em 2011. Participaram do processo de seleção 129 candidatos, resultando 32 selecionados, uma demanda de 4,0 candidatos por vaga. As atividades do curso iniciaram se no dia 04 de maio e foram finalizadas no dia 31 de maio de 2012. A estrutura curricular do curso foi composta por 19 disciplinas. Quatro discentes solicitaram o cancelamento da 
matrícula, dois reprovaram em disciplinas e cinco não foram aprovados no TCC. No total, 21 alunos concluíram o curso (18).

A sexta turma obteve um número menor de participantes com relação as turmas dos anos anteriores, participaram do processo seletivo 84 candidatos, resultando 29 selecionados uma demanda de 2,8 candidatos por vaga. As atividades do curso iniciaramse dia 09 de maio, e foram finalizadas em 14 de dezembro de 2012. Apenas dois alunos reprovaram por nota. O menor índice até então comparada com as outras turmas. No total $94 \%$ dos alunos concluíram o curso (19).

Com a participação de 130 candidatos no processo seletivo, e uma demanda de 4,3 por vaga, a sétima turma (20), deu início as atividades no dia 09 de abril de 2014. Foram selecionados e matriculados 30 alunos. Esta turma contou com a participação de um aluno estrangeiro convidado. Com 486 horas-aulas, o curso finalizou suas atividades em 12 de dezembro do mesmo ano, com aprovação de 29 alunos.

A seleção dos alunos sempre deu-se por etapas eliminatórias e classificatórias, envolvendo desde aplicação de prova de Português e exigência de redação sobre tema da atualidade, como análise de Currículo, Carta de Intenções e entrevistas.

O sítio da EFG - Fiocruz Brasília não dispõe de informações detalhadas sobre o curso. A Transparência para o público acarreta maior procura, pois informações básicas sobre estrutura curricular e o processo seletivo, aumenta a chance de maior número de interessados, já é evidente com os dados atuais sobre o interesse e procura do curso.

Também não foram apontados nos relatórios acadêmicos, avaliação do aluno referente ao curso de modo geral e a instituição de ensino. O feedback dos alunos serve como parâmetros para modificações relacionadas à estrutura curricular do curso, avaliação de docente, projeto pedagógico. As avalições podem vir como forma positiva ou negativa, no entanto, servem para justificar se o modelo estrutural do curso adotado atualmente está sendo efetivo, ou se há necessidade de modificações. Não foram citados nos relatórios se ocorrem reuniões pedagógicas com docentes, este fato implica na elaboração de diretrizes para aprimoramento do curso, assim como avaliar as demandas oriundas dos alunos referentes às disciplinas.

Com relação aos Trabalhos de Conclusão de Curso, a Biblioteca da EFG Brasília não tem disponível em seu acervo todas as monografias dos egressos constante em seu banco 
de dados. Como dito anteriormente, a maioria dos trabalhos estão na guarda da Secretaria Acadêmica e, portanto, fora do acesso dos alunos e interessados.

De acordo com o relatório acadêmico 212 alunos passaram pelo curso, mas somente 178 se formaram, mostrando uma evasão escolar de $16 \%$.

O número de evasão escolar é um fenômeno social complexo, definido como interrupção no ciclo de estudos. É um problema que preocupa as instituições de ensino em geral, sejam públicas ou particulares, pois a saída de alunos provoca graves consequências sociais, acadêmicas e econômicas (21). No caso em específico da evasão relacionada ao curso de Direito Sanitário, um dos índices prejudiciais é o econômico, já que o investimento aplicado no aluno, feita pelo Estado, não teve o retorno esperado. A oferta do curso não tem custo para o aluno, é de forma gratuita é ofertada pela Fiocruz Brasília.

\section{Considerações Finais}

A Especialização em Direito Sanitário oferece relevantes contribuições para a educação continuada, o que pode ser evidenciado pela crescente procura por vaga em todos os processos seletivos. O curso mostrou que diversos profissionais têm interesse em fazer parte da especialização, principalmente os da área da saúde e do direito, além de estudantes recém-graduados. A Escola Fiocruz de Governo incentiva que os servidores se qualifiquem em cursos oferecidos pela instituição, mantendo o desafio para a formação de profissionais de saúde para atuar no SUS.

Com relação às lacunas encontradas nos relatórios acadêmicos, cabe à secretária acadêmica juntamente com a coordenação do curso, discutir mecanismos de aprimoramento do projeto político pedagógico para efetivação da gestão de qualidade, com cumprimento das diretrizes estabelecidas pelo MEC e Conselho Nacional de Educação.

Cabe ao Ministério da Educação da Educação e ao Conselho Nacional de Educação, zelar por uma regulação que seja efetiva na garantia dos critérios de qualidade do ensino. $A$ Resolução de 2014 (MEC/CNA/CES), já estabeleceu critérios para o acompanhamento de cursos por meio de levantamento de dados em todas as instituições credenciadas no sistema federal de ensino. A iniciativa de regulação e supervisão significa um avanço para a qualidade dos cursos lato sensu.

Estudar as constantes mudanças conjunturais no Sistema único de Saúde, as normas jurídicas que regulam estas ações, fazem parte do estudo do Direito Sanitário. Desde 2006, 
o curso vem ganhando forças e devagar conseguiu construir uma forte referência entre os poucos programas de pós-graduação da área, no País. Uma iniciativa exitosa que já conta com a formação de 178 especialistas, número este que poderiam ser maiores se caso houvesse ampliação de novas turmas. A relação aluno, docente e disciplina mostram-se positiva. Poderiam incluir neste meio, feedbacks com a opinião do aluno acerca do curso, pontos relevantes, negativos e sugestões futuras. Este retorno não consta nos relatórios acadêmicos. Ouvir a opinião de quem passa pela especialização, ajuda a corrigir falhas e fortalece a estrutura acadêmica.

Este trabalho constatou importantes reflexões sobre os 9 anos de oferta de curso, que de todas as informações citadas, é importante destacar que a atual situação política, em que se atuam para o desmanche do SUS, ter um curso que discute as políticas de saúde e capacita seus discentes para atuar de forma jurídico-legal efetiva no serviço, demonstra relevante contribuição para o fortalecimento do SUS, com atuação de trabalhadores empenhados e qualificados que atuam na saúde pública e lutam pelas garantias sociais existentes.

\section{Referências}

1. Nunes ED, Ferreto EL, Barros FN. A pós-graduação em Saúde Coletiva no Brasil: trajetória. Ciência \& Saúde Coletiva. 2010; 15(4):1923-1934. Disponível em: http://www.redalyc.org/pdf/630/63018747008.pdf [Acesso em 10.set.2017]

2. Fonseca M, Fonseca da MD. A gestão acadêmica da pós-graduação lato sensu: 0 papel do coordenador para a qualidade dos cursos. Educ. Pesqui. São Paulo. 2016; 42(1):151-164.

3. Ministério da Educação. Recomendações para a oferta de cursos de PósGraduação Lato Sensu. Disponível em: http://portal.mec.gov.br/pos-graduacao/pos-lato-sensu [Acesso em 10.set.2017]

4. Ministério da Educação. Resolução do MEC/CNE/CES, nำ2, de 12 de fevereiro de 2014. Institui o cadastro nacional de oferta de cursos de pós-graduação lato sensu (especialização) das instituições credenciadas no Sistema Federal de Ensino. Disponível em:

http://portal.mec.gov.br/index.php?option=com docman\&view=download\&alias=15177rces002-14\&category slug=fevereiro-2014\&ltemid=30192 [Acesso em 10.set.2017]

5. Fonseca MD. Contribuições ao debate da pós-graduação Lato Sensu. Revisa Brasileira de Pós-Graduação. 2004; 1 (2):173-182. 
6. Fundação Oswaldo Cruz. Acesso à informação. Base jurídica. Disponível em: https://portal.fiocruz.br/pt-br/content/base-jur\%C3\%ADdica [Acesso em 10.set.2017]

7. Brasil. Decreto no 8.932, de 14 de dezembro de 2016. Aprova o Estatuto e o Quadro Demonstrativo dos Cargos em Comissão e das Funções de Confiança da Fundação Oswaldo Cruz - FIOCRUZ, remaneja cargos em comissão e funções de confiança, substitui cargos em comissão do Grupo Direção e Assessoramento Superiores - DAS por Funções Comissionadas do Poder Executivo - FCPE. Disponível em:

https://www.planalto.gov.br/ccivil 03/ ato2015-2018/2016/decreto/d8932 [Acesso em 10.set.2017]

8. Fiocruz Brasília. Relatório Final. Il Curso de Especialização em Direito Sanitário. 2006. (mimeo)

9. Fiocruz Brasília. Especialização. Disponível em: https://www.fiocruzbrasilia.fiocruz.br/ [Acesso em 10.set.2017]

10. Aith F. Curso de Direito Sanitário: a proteção do direito à saúde no Brasil. São Paulo: Quartier Latin, 2007.

11. Universidade de Brasília. Faculdade Ciências da Saúde. Saúde Coletiva. Disponível em: https://fs.unb.br/saude-coletiva [Acesso em 10.set.2017]

12. Amaral FM. O Direito Sanitário no Brasil: um panorama do ensino especializado e sua práxis restrita. Revista Cadernos Ibero-Americanos de Direito Sanitário. 2015; 4(4):105-122.

13. Alves SMC. A formação em direito sanitário: um diálogo possível a partir da interdisciplinaridade. In: Conselho Nacional de Secretários de Saúde. (org.) Direito à Saúde. Brasília: Conass, 2015.

14. Fundação Oswaldo Cruz. Relatório Final. VII Curso de Especialização em Direito Sanitário. Brasília. 2015 (mimeo)

15. Fundação Oswaldo Cruz. Relatório Final. II Curso de Especialização em Direito Sanitário. Brasília. 2006 (mimeo)

16. Fundação Oswaldo Cruz. Relatório Final. III Curso de Especialização em Direito Sanitário. Brasília. 2008 (mimeo)

17. Fundação Oswaldo Cruz. Relatório Final. IV Curso de Especialização em Direito Sanitário. Brasília. 2009 (mimeo)

18. Fundação Oswaldo Cruz. Relatório Final. V Curso de Especialização em Direito Sanitário. Brasília. 2011 (mimeo)

19. Fundação Oswaldo Cruz. Relatório Final. VI Curso de Especialização em Direito Sanitário. Brasília. 2012 (mimeo) 
20. Fundação Oswaldo Cruz. Relatório Final. VII Curso de Especialização em Direito Sanitário. Brasília. 2014 (mimeo)

21. Baggi SAC, Lopes LA. Evasão e avaliação institucional no ensino superior: uma discussão bibliográfica. Revista de Avaliação da Educação Superior. 2011; 16(2):255-374.

Recebido em:26.12.2017

Aprovado em: 6.3.2018

\section{Como citar este artigo:}

Oliveira LG. Análise da formação pedagógica Lato Sensu em Direito Sanitário da Escola de Governo em Saúde - Fiocruz Brasília. Revista Cadernos Ibero-Americanos de Direito Sanitário. 2018 jan./mar, 7(1):111-126 